Culture et histoire dans l'espace roman

$4 \mid 2010$

Les représentations du corps dans la litterature latinoaméricaine

\title{
Retórica del fragmentarismo : la representación del cuerpo en Mundar de Juan Gelman
}

\section{María Victoria Utrera Torremocha}

\section{(2) OpenEdition}

\section{Journals}

Edición electrónica

URL: https://journals.openedition.org/cher/8544

DOI: $10.4000 /$ cher.8544

ISSN: 2803-5992

\section{Editor}

Presses universitaires de Strasbourg

\section{Edición impresa}

Fecha de publicación: 30 junio 2010

Paginación: 75-86

ISBN: 978-2-35410-007-0

ISSN: 1968-035X

\section{Referencia electrónica}

María Victoria Utrera Torremocha, «Retórica del fragmentarismo : la representación del cuerpo en Mundar de Juan Gelman», reCHERches [En línea], 4 | 2010, Publicado el 15 diciembre 2021, consultado el 25 enero 2022. URL: http://journals.openedition.org/cher/8544 ; DOI: https://doi.org/10.4000/cher. 8544

$\mathrm{Ce}(\mathrm{tte})$ œuvre est mise à disposition selon les termes de la Licence Creative Commons Attribution Pas d'Utilisation Commerciale - Partage dans les Mêmes Conditions 4.0 International. 


\title{
Retórica del fragmentarismo: la representación del cuerpo en Mundar de Juan Gelman
}

\author{
María Victoria Utrera Torremocha \\ Universidad de Sevilla
}

$\mathrm{E}$ s bien conocida la idea de Marcel Proust de que los libros bellos han sido escritos en una especie de lengua extranjera. Quizás sean los poetas los que con más pujanza han demostrado a lo largo de la historia literaria que son especialmente capaces de inventar una lengua, de dar un sentido nuevo a las palabras, como pretendían los grandes maestros simbolistas del siglo XIX. En efecto, el gran escritor inventa dentro de la lengua una lengua nueva. Extrae de ella nuevas estructuras y nuevos sentidos. O, como diría Gilles Deleuze, llevándola a sus límites, «la hace delirar» (Deleuze 1996: 9). Juan Gelman coincide en que hay que «hundir las palabras en la realidad hasta hacerlas delirar como ella» (Dalmaroni 1993 100). En esa concepción de la literatura, según Deleuze, no importaría la mímesis ni la representación, sino el propio lenguaje, que va hacia lo informe: "Escribir es un asunto de devenir, siempre inacabado, siempre en curso, y que desborda cualquier materia vivible o vivida» (Deleuze 1996: 11). Frente al mal novelista que indica o dice, el buen novelista, como Balzac, hace sin indicar y sin decir. Una tercera categoría se produce «cuando decir es hacer»; entonces el escritor «hace tartamudear la lengua como tal» (Deleuze 1996: 150). El lenguaje hace, se torna perlocutivo. Esta lengua - una lengua balbuciente -, estaría, según Deleuze, en un desequilibrio perpetuo respecto con el modelo, de modo que el escritor «talla en su lengua una lengua extranjera y que no preexiste» (Deleuze 1996: 153). Se trata de un desequilibrio equivalente a los textos de la ruptura y el uso de una lengua "redistribuida", de la que habló Roland Barthes. La deconstrucción de la lengua estaría dentro de los límites 
de la "estética de la oposición" que ha estudiado Yuri Lotman. No obstante, no hay que perder de vista que esta lengua "desequilibrada" es también parte del sistema y no está ya tanto fuera de él, sino en sus límites (Lotman 1970: 345ss.; Barthes 1982: 15ss.) En este contexto estético hay que situar la poesía de Juan Gelman.

En la distinción de Roland Barthes, los textos de goce estarían construidos sobre una lengua y una cultura en pedazos. Este tipo de textos son completamente intransitivos en la medida en que es el lenguaje, como cuerpo y como tejido, el protagonista único de la articulación textual, pero no el sentido. En esta línea, la poesía de Gelman podría adscribirse a la modernidad literaria, que Barthes relaciona con las utopías del lenguaje. Sería ésta, según Harold Bloom, una tarea propia de los escritores fuertes que, en un diálogo con la literatura preexistente, han de encontrar un estilo al límite de la tradición y de la norma (Bloom 1991). Así lo ve el mismo Gelman al referirse a la creación poética de ciertos autores como Cervantes o Lope de Vega, en los que destaca el empleo de neologismos, la invención y el enriquecimiento de la lengua, muestra de la vida de ésta en cambio permanente: "La lengua expande el lenguaje para hablar mejor consigo misma». La poesía abriría las puertas a los espacios vacíos: «Hay millones de espacios sin nombrar y la poesía trabaja y nombra lo que no tiene nombre todavía» (Gelman 2008a: 122).

Pero para Gelman, además, la experiencia del horror vivido va ligada al concepto de la poesía, cuyo papel ante la realidad es el consuelo y la denuncia. En efecto, el poeta se sitúa él mismo dentro de la modernidad literaria, en la línea de autores como Cervantes, Kafka o Joyce, destacando elementos como el vacío, la muerte anónima, la transgresión o la fractura del sujeto (Gelman 2008a: 121). A menudo la crítica sobre Gelman se ha referido a la importancia que tiene en él la denuncia y el compromiso social. Igualmente, se ha insistido en la importancia de la experimentación con el lenguaje desde sus inicios y en todos sus poemarios. Existe, por tanto, un hacer en el lenguaje, una perlocución indiscutible en toda su trayectoria poética, que no es incompatible con la referencia, o, si se quiere, con la imitación o la transitividad. En su último libro, Mundar (2008), se percibe un descenso del tono irónico y de la experimentación gráfica y lingüística. Sin embargo, persisten procedimientos retóricos de capital importancia que inciden en el efecto perlocutivo: el uso tropológico del lenguaje, concretamente de la sinécdoque y de la metonimia, también la metáfora, que se complementa con otros recursos de especial interés como la antítesis. Se 
unen estas y otras estrategias retóricas a la ya mencionada problematización del sentido, que hay que asociar especialmente a las imágenes corporales. La imagen fragmentada del cuerpo y, por ende, de la realidad, no es ajena a la del mismo sujeto y a la de la conciencia (Fabry 2003). Por eso, es importante destacar que en Gelman el cuerpo y su fragmentación retórica no han de ser entendidos simplemente como un tema, sino como una expresión, como un lenguaje. Las imágenes corporales en Mundar adquieren, además del sentido de denuncia que venía siendo habitual en anteriores poemarios, un nuevo alcance: el de la dimensión temporal vinculada a la identidad poética y a la reflexión metapoética, añadido e intensificado en los últimos libros de Gelman y particularmente en Mundar.

La expresión del cuerpo tiene, pues, en los tropos sus principales recursos. La consecuencia de este modo retórico, sobre todo por el empleo de la sinécdoque, es un acusado fragmentarismo, no ajeno a la estética moderna y postmoderna. Ya $\mathrm{M}^{\mathrm{a}}$ Ángeles Pérez López notó que en su primer libro Gelman empleó objetos que metonímicamente nombraban al protagonista (Pérez López 2005: 16). La autora ha puesto de manifiesto la importancia de la descomposición de la realidad en fragmentos, destacando, en este sentido, las partes del cuerpo - pecho, garganta, pies, tripa -, los objetos personales - cucharita -, además de los animales y los árboles. Se trata de un fragmentarismo que se produce a través del "procedimiento central de la metonimia» (Pérez López 2005: 32; Achugar 1985: 95-102). Pero no se trata sólo de la metonimia, sino de otros recursos tropológicos que potencian la visión analítica. Los correlatos objetivos simbólicos del poeta, estudiados por críticos como Saúl Yurkievich (1995) o Edgar O’Hara (1993), tienen en el terreno concreto de la corporeidad una importancia que ha sido inexplicablemente poco destacada. Se abordarán en esta breve comunicación algunas conclusiones al respecto derivadas del análisis de su último libro.

La denuncia del poder violento en Mundar se produce por formas que implican disolución y cosificación y por otros recursos retóricos desmitificadores. En el poema titulado "Así, así», por ejemplo, la piel revienta y se recuerda el gran fondo de las fosas, pero éstas no tienen los esperados huesos, sino, en su lugar, una inocencia de noches. Se trata de la 
mezcla antitética ${ }^{1}$ de materia y espíritu que va a ser característica especial de este poemario y que ya está anunciada en libros anteriores del autor:

La piel revienta/el alma

o lo que así se llama /

no se quiere sentar/ ¿qué ciencia

le dará paz? / no tiene

otros parientes que el absurdo

de reír victorias que no son /

resplandece la luna en

noches que burlan su destino y

¿quién podría nombrar al pasado

de este presente seco? / el gran fondo

de las fosas que el poema recuerda

no tiene huesos sino

la inocencia de noches caminadas

por el miedo a no ser $/ 2$

El recurso a la antítesis en el concepto del cuerpalma gelmaniano juega un papel fundamental en la imagen del cuerpo en la poética del escritor. Gelman deconstruye la vieja dicotomía entre el cuerpo y el alma, entre cuerpo y espíritu, presente desde la filosofía aristotélica y otros textos antiguos, y que se perpetúa en toda la filosofía, los santos padres y la teología medieval y renacentista hasta hoy.

Frente al poder opresor y dictatorial, la identidad propia también se construye fragmentariamente con imágenes corporales y es complementaria con la identidad, también construida fragmentariamente, de los otros. De este modo, el sistema social entre yo-otros y poder se representa corporalmente. Los elementos corpóreos más frecuentes para esta representación de la dispersión son: el rostro, la sangre, las manos y los brazos ("Accidentes», "Amistades», "Compañeros», «Islas», «La extranjera», «Regiros», «Tango », etc.). Son los fundamentos de la identidad social y de la memoria de un pasado común que vuelve.

Los brazos y las manos suelen vincularse a la ausencia y a los ahogados desaparecidos. La sinécdoque de los brazos funciona bien para expresar la imposibilidad de la unión y la falta de asidero, a lo que se suma, por ejemplo,

1 Algunos críticos han destacado ya los elementos antitéticos y paradójicos en Gelman y la experimentación con el lenguaje. Véase, por ejemplo, Pérez López 2002, Pérez López 2005, Dalmaroni 1993, Dalmaroni 1998, Gabbay 2005, Uribe 1998, Cortázar 1988, Stierle 1977.

2 Gelman 2008b: 136. Las referencias a la página de los poemas se harán a partir de ahora en el propio cuerpo del texto, entre paréntesis y por esta misma edición. 
en el poema «La pregunta», la metáfora, tan frecuente en Gelman, de los perros: "Se apagaban los brazos,/ los perros en el fondo,/ ayes que no pudieron decir ay» («La pregunta», p. 52). También los ahogados y el vacío del océano se expresa a través de manos, pero a menudo no se mencionan directamente los cuerpos, con una función clara de evitar la identidad de los ahogados y de destacar el anonimato de tantos muertos convertidos tan sólo en manos. La sinécdoque potencia el horror y la despersonalización y remite a la multitud sin nombre: «Eso, no saber/ nada, ser nada en el/ océano de las manos perdidas» («Canción», p. 60).

En alguna ocasión los ahogados, que se convierten en cuerpos que navegan, se presentan efectivamente como cuerpos completos, mencionados como tales y asociados al tiempo que vuelve. Entonces se vinculan a los vacíos que lloran y al pasado no sólo personal sino del propio país, es decir, al pasado histórico. Es interesante comprobar cómo Gelman da a estos cuerpos una dimensión no sólo temporal sino espacial. El poema "Volver» es especialmente sintomático a este respecto, porque, además, los cuerpos están concebidos como un colectivo, lo que incide en el anonimato de los muertos y el horror del genocidio:

El pasado vuelve cuando desaparece. Vacíos que lloran en sus países

y en arrabales interiores gritan.

¿Qué vale la cerviz golpeada mucho?

Oh cuerpos que navegan

la sangre todavía y en

el viejo amor se juntan.

El miedo en rostros ya tocados

es piedra que repite su piedra.

Se hinchan los ojos con

las cobardías de este tiempo, sentadas

en sillas de su olvido.

Además de la metáfora, el escritor se sirve de la dilogía: son cuerpos que navegan porque son ahogados y que navegan la sangre de los otros porque siguen viviendo en los otros, al ser de su sangre. Los rostros anónimos se vuelven piedra, nueva metáfora de muerte. Todo es unidad doliente. La antigua correspondencia entre naturaleza y ser actúa una y otra vez: no hay límite entre las cosas y los vivos o los muertos. 
Los ojos suelen ser expresión del dolor y también de la conciencia vigilante del poeta; se extrapolan a los ojos de la tierra y a los de las heridas, con lo que existe, al igual que sucede en otros aspectos de la poesía gelmaniana, una deseada confusión de los planos humano y natural. Los ojos son manifestación de los otros y se relacionan con la luz, de ahí su sentido de denuncia poética:
Alguien llora la carta
que va a escribir. Afuera
se desmembrana el día en sus agüeros.
Una luz que viene de
millones de ojos que se juntan
y el vapor de la furia inmaculado
cambian las fechas de la muerte.
El fuego interior cuece
viejas iras para
que alguien les ponga nombre. («La carta», p. 41)

Un motivo más tópico es el de la sangre, que simboliza a menudo la identidad de toda la humanidad. También se presenta la sangre como metonimia de los cuerpos asesinados - manos manchadas de sangre, etc. Muy frecuente la sangre está asociada a la violencia y, por tanto, a la denuncia de la misma.

El recuerdo constante de los desaparecidos se expresa a través de la imagen sinecdótica de sus rostros. Este modo retórico acentúa el carácter fantasmal de los ausentes y potencia el vacío social. Los rostros de los idos son los de los presentes: existe nuevamente una correspondencia, como la hay entre pasado y presente, como la que hay entre la naturaleza y los hombres. En el poema «Debajo», Gelman declara: «La / anticipación de la mañana / talla tu rostro en mí» (p. 23). La comunión con el otro es completa. Pero hay aquí otras implicaciones, si se considera que esa identificación es efecto de una naturaleza artífice y, por tanto, personificada. Convendría quizá recordar la cita de Deleuze cuando afirma que el buen escritor «talla en su lengua una lengua extranjera y que no preexiste» (Deleuze 1996: 153).

El carácter fantasmal de los desaparecidos, claramente logrado por la sinécdoque de los rostros, se acentúa cuando aparecen con niebla y como muertos con vida:

Aparecen con niebla los rostros muertos hacia arriba y compañeros que no se oyen miran el mundo. 


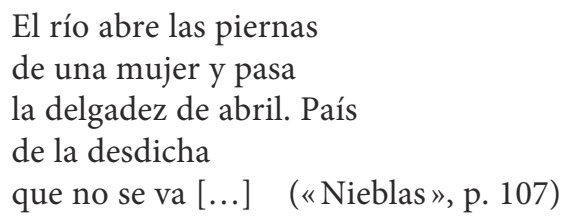

En la crítica sobre la obra de Gelman se ha insistido en la importancia de la poesía no sólo como denuncia, sino como recuperación de la memoria personal e histórica. En las representaciones corporales es evidente que las relaciones entre el yo y mundo se corresponden con una relación temporal entre la identidad poética del yo y el tiempo de la historia. Así, el cuerpo es también símbolo del pasado y del sufrimiento ${ }^{3}$.

El rostro se convierte en la imagen del recuerdo. Los rostros son las almas en pena. Estas almas viven permanentemente en la memoria del poeta que las recupera a través de la poesía:

Para San Agustín, la memoria es un santuario vasto, sin límite, en el que se llama a los recuerdos que a uno se le antojan. Pero hay recuerdos que no necesitan ser llamados y siempre están ahí y muestran su rostro sin descanso. Es el rostro de los seres amados que las dictaduras militares desaparecieron. Pesan en el interior de cada familiar, de cada amigo, de cada compañero de trabajo, alimentan preguntas incesantes (Gelman 2008a: 122).

El rostro es, por tanto, también metáfora de la poesía, al identificarse escritura y alma. De este modo existe una identificación entre rostro / cuerpo y alma / escritura. La escritura es cuerpo representado sinecdóticamente con la palabra rostro.

Los asesinos también se manifiestan corporalmente y de modo fragmentario y tropológico - lenguas con escorpiones, almas secas por la ausencia de alma, soledad de gris vestida - y se caracterizan con frecuencia como cuerpos muertos y vacíos («Velocidades», «A saber»).

Un poema significativo de la disgregación es «Roces». Los fragmentos corporales que se mencionan indican la muerte y desaparición del niño asesinado. Es evidente la violencia del poder por distintas imágenes metonímicas, causa de sufrimiento y de muerte: cuchillo, mar, clavo. El niño ha sido arrojado al mar, pero lo que se ahoga en el texto es una serie

3 Elena Tamargo ha estudiado, a partir de los trabajos de Maurice Merleau-Ponty, las relaciones entre el pasado y las representaciones corporales en la poesía de Gelman. En este sentido, el cuerpo es la instancia de la que se parte para la relación con el mundo en un proceso de percepción y de conocimiento en el presente y también en un reconocimiento y percepción del pasado a través del recuerdo doloroso (Tamargo 2000). 
de elementos, que, en una enumeración retórica, responden a su rostro, sus palabras y sus deseos, sus ojos heridos, el clavo que los cerró y los asesinó y su voz metonímicamente presentada como lengua:

Han clausurado huesos

del niño por quién sabe. Un soplo

del cuchillo apagó

el mal sabido mar que pudo ser.

Se ahogan el rostro, los

espérames, el clavo

que te clavó de ojos cerrados

contra una lengua. (p. 36)

En Gelman no existe, en realidad, separación entre los planos corpóreo y espiritual. El dolor, como se ha comprobado ya, une ambos niveles, en perfecta correspondencia, de ahí, como en la poesía mística, las mezclas antitéticas, los juegos espacio-temporales, el concepto de dentrofuera y la continua interrelación entre pasado y presente. En la unión entre cuerpo y alma uno de los elementos centrales es el corazón. No en vano es una metáfora lexicalizada ya por la tradición literaria:

Si el dolor es físico y de alma

el sufrimiento, díganme

cómo se distribuye la pasión

del cuerpalma, sus bestias

volátiles, distintas

de la eternidad. ¿Se separan

cuando los números profundos

dijeron basta y lo

que calentaba el corazón se fue? («Distribuciones», p. 99)

En la concepción de la poesía no ha de separarse el pensamiento - la cabeza - del sentimiento - el corazón. Para Gelman existe una identidad absoluta entre cuerpo y escritura: «El poema que estaba en la cabeza/ del corazón se fue» («Amistades», p. 20). En el poema «Nacer nacer» los libros suben «del corazón que el deseo / tapó de luz!» (p. 93). No cabe duda de que la palabra poética también está concebida corporalmente. Así se aprecia en la breve poética desarrollada en «Escondrijos», donde se entiende la palabra como nuevo cuerpo en el cuerpo del poeta y que ha de luchar contra su piel, es decir, su superficie, para penetrar en lo más hondo:

El envión de la palabra la

lleva al borde que no

puede cruzar. Gime ahí 
como una grulla loca, un desperdicio del destino.

La saludo, la amo cuando

se instala como cuerpo en

mi cuerpo contra

la piel del día, las

sombras que se agitan

en escondrijos de la juventud

como si fueran de verdad. (p. 21)

No existe distinción entre el cuerpo y el alma. El concepto del dentrofuera, que asocia claramente a la creación literaria, es la clave que permite unir la visión y la realidad, el presente y el pasado:

La mecánica del alma no

significa estar

adentro. Caminar, respirar, ver,

escuchar, los demás,

no significa estar afuera.

El dentrofuera es un temblor tardío

y está ahí:

en una lejanía

que mece con

palabras que vencieron al fuego. («Lejanías», p. 32)

Como recreación corporal, la poesía es lucha contra la opresión - piedra -, posee realidad corporal para manifestarse - garganta, lengua, boca -, tiene conciencia y visión propia - ojos -, sentimientos y sueños - pecho, corazón, ojos -. Para Gelman, las palabras son materia y no sólo tiempo, y están en las entrañas, unidas a una piedra que no acaba ( La pretensión»). En esta poética, la escritura se concibe corporalmente. Por eso, muy a menudo se asimila, siguiendo las pautas tradicionales, a la metáfora del pájaro. En el poema "El estornino", los cómplices hierven en la sangre y escriben en la libreta de la frente de adentro. Materia y espíritu es una misma cosa: el dentrofuera.

La poesía es también un modo de conocimiento propio, de saberse. En el poema "Dice», a modo de poética, el lenguaje es un continuo cambio que el poeta ha de descubrir y con el que mantiene una relación corporal - una herida -. Está presente en el texto el antiguo tópico del je ne se quoi: se dice lo que no se entiende, que habría que relacionar, en principio, con el lenguaje intransitivo de la modernidad literaria; al poeta se le presenta el 
ser que no es. Pero es entonces cuando el poeta afirma que quiere ser útil y rechaza - y reconoce - la deriva de la lengua:

¿Quién / qué? / Eso que oigo

y no entiendo

lo digo yo. Se presenta

el ser que no es

y los pájaros llaman al crepúsculo.

Ojalá me dieran un lugar

en su nido para ser útil/ no

esta deriva de la

lengua que me heriste en la cuna.

No te conozco todavía.

Te cavo

para saber quién soy.

¿Se puede afirmar la intransitividad del lenguaje? ¿Se puede hacer en el caso de Juan Gelman? No lo creo. El alcance perlocutivo de su poesía va siempre a la realidad. Existe un claro paralelismo entre el propósito de cambiar la lengua y el deseo de cambiar el mundo. Es evidente el compromiso ético (Barthes 1982: 83, 109, 129) y estético. Ahí reside la modernidad de Gelman.

La mejor manera de denuncia de la deshumanización y de la muerte es presentar al sujeto como cuerpo, indicio de vacío y de muerte, y presentarlo de manera desmembrada, como síntoma de descomposición. El procedimiento cumple, pues, una doble función: la quiebra de la identidad personal y la quiebra de la identidad social. Según Roland Barthes, dentro de la visión analítica del lenguaje, el cuerpo sólo puede "atraparse» si es fragmentado. Así, a propósito de Sade, afirma:

El cuerpo total está fuera del lenguaje, sólo llegan a la escritura fragmentos del cuerpo; para que se vea un cuerpo, o bien hay que desplazarlo, refractarlo en la metonimia de su vestimenta, o hay que reducirlo a una de sus partes; la descripción se vuelve entonces visionaria, se recupera la felicidad de la enunciación acertada (quizá porque existe una vocación fetichista del lenguaje) (Barthes 1997: 150).

4 En $S / Z$, Barthes se ha referido también a la parcelación en la manera de presentar el cuerpo femenino, diseminado y dividido - pierna, pecho, hombro, cuello o mano -. A este respecto, indica que la mujer cortada en pedazos no es sino «una especie de diccionario de objetos-fetiches ». El hecho de que el artista, como creador, reúna las partes en un cuerpo completo no impide la conciencia del vacío (Barthes 1980: 93). 
Más allá del componente visionario de Sade, lo que sí es especialmente significativo en Gelman, y aquí hay que entroncar con la lengua desequilibrada e inventada de Deleuze, es que existe, en virtud de los procedimientos retóricos estudiados, una enunciación acertada. La escritura se asocia a la imaginación y a la vida, a la vivencia y sus posibilidades, a la creatividad individual en el lenguaje:

Esto exige que el poeta despeje en sí caminos que no recorrió antes, que desbroce las malezas de su subjetividad, que no escuche el estrépito de la palabra impuesta, que explore los mil rostros que la vivencia abre en la imaginación, que encuentre la expresión que les dé rostro en la escritura (Gelman 2008a: 122).

En esta trascendencia interna se encuentra la verdad propia y la del mundo. La creación permite descubrir la realidad, denunciar los abusos, hacer vivir a los olvidados. Se sabe que uno de los grandes problemas para el poeta Gelman es cómo hablar del horror y seguir escribiendo poesía. En el discurso que ofreció cuando fue galardonado con el Premio Miguel de Cervantes, se pregunta cuál es la función de la poesía en estos tiempos de terror y de guerra. Ésta es la respuesta:

Y es algo verdaderamente admirable en estos Dürftiger Zeite, estos tiempos mezquinos, estos tiempos de penuria, como los calificaba Hölderlin preguntándose Wozu Dichter, ¿para qué, poetas? ¿Qué hubiera dicho hoy, en un mundo en el que cada tres segundos y medio un niño menor de cinco años muere de enfermedades curables, de hambre, de pobreza? ¿Cuántos habrán fallecido desde que comencé a decir estas palabras?, pienso. Pero ahí está la poesía: de pie contra la muerte (Gelman 2008a: 120).

Por eso para Gelman, Adorno se equivocó al pensar que era imposible la escritura después de Auschwitz, como demuestra la obra de Paul Celan, o la de Kenzaburo Oé, después de Hiroshima y Nagasaki. Se puede escribir poesía después del horror; pero ha de ser otra escritura. El horror y su descomposición se expresa en la poesía gelmaniana en un lenguaje que hace lo que dice: es un lenguaje herido. No hay separación entre poesía y cuerpo, porque no la hay para el poeta entre realidad espiritual y material. Todo es uno en el concepto unitario de cuerpalma en correspondencia simbólica con una realidad que nunca es ajena ni a la poesía ni al lenguaje. 


\section{Bibliografía}

Achugar, Hugo, 1985, «La poesía de Juan Gelman o la ternura desatada », Hispamérica, no 41, 1985, p. 95-102.

Barthes, Roland, 1980, S/Z (1970), Madrid, Siglo XXI.

Barthes, Roland, 1982, El placer del texto. Lección inaugural (1973, 1978), Madrid, Siglo XXI.

Barthes, Roland, 1997, Sade, Fourier, Loyola (1971), Madrid, Cátedra.

Bloom, Harold, 1991, La angustia de las influencias, Caracas, Monte Ávila.

Cortázar, Julio, 1988, «Prólogo» a Juan Gelman, Interrupciones I, Buenos Aires, Libros de Tierra Firme, Ediciones Último Reino.

Dalmaroni, Miguel, 1993, Juan Gelman contra las fabulaciones del mundo, Buenos Aires, Almagesto.

Dalmaroni, Miguel, 1998, «El pasaje hacia el antidiscurso en la crítica poética de Juan Gelman», en Jorge Fornet (ed.), Al borde de mi fuego. Poética y poesía hispanoamericana de los sesenta, Alicante, Murcia, Universidad de Alicante, p. 99-105.

Deleuze, Gilles, 1996, Crítica y clínica (1993), Barcelona, Anagrama.

Fabry, Geneviève, 2003, "Continuidades y discontinuidades en la poesía de Juan Gelman. Una glosa de Incompletamente», Foro Hispánico. Revista Hispánica de Flandes y Holanda, La literatura argentina de los años 90, n²4, 2003, p. 97-110.

Gabbay, Cinthia, 2005, "Cólera buey o la palabra torrente», Anales de Literatura Hispanoamericana, no 34, 2005, p. 197-206.

Gelman, Juan, 2008a, «De pie contra la muerte», Transatlántica de educación, n 4 , 2008, p. 119-122.

Gelman, Juan, 2008b, Mundar, Madrid, Visor.

Lotman, Yuri M., 1970, Estructura del texto artístico, Madrid, Istmo.

O’Hara, Edgar, 1993, «Danza de las cucharas: Tríptico vallejiano », La Torre, n 25 , 1993, p. 37-52.

Pérez López, Ma Ángeles, 2002, «Notas a unas notas (Paradoja y poesía en Juan Gelman) ", La Página, no 47, 2002, p. 41-51.

Pérez López, Ma Ángeles, 2005, "Juan Gelman: ese oficio ardiente llamado poesía », introducción a Juan Gelman, Oficio ardiente, Salamanca, Universidad, p. 9-87.

Stierle, Karlheinz, 1977, "Identité du discours et transgression lyrique», Poétique, $\mathrm{n}^{\circ} 33,1977$, p. 422-441.

Tamargo, Elena, 2000, Juan Gelman: poesía de la sombra de la memoria, México, Universidad Iberoamericana.

Uribe, Lilián, 1998, «Rescatar el esplendor de la palabra: la poesía de Juan Gelman », en Jorge Fornet (ed.), Al borde de mi fuego. Poética y poesía hispanoamericana de los sesenta, Alicante, Murcia, Universidad de Alicante, p. 95-98.

Yurkievich, Saúl, 1995, «La violencia estremecedora de lo real», en Lilián Uribe (ed.), Como temblor del aire: la poesía de Juan Gelman. Ensayos críticos, Montevideo, Vintén, p. 125-142. 


\title{
Le corps dans Tejas Verdes. Diario de un campo de concentración chileno d'Hernán Valdés : une mémoire de la barbarie chilienne
}

\author{
Maria Grazia Spiga Bannura \\ Université de Paris XII
}

Les régimes totalitaires du $\mathrm{XX}^{\mathrm{e}}$ siècle ont révélé un danger insoupçonné jusqu'alors: la suppression de la mémoire.

Tzvetan Todorov, Mémoire du mal, tentation du bien

¿ ieu de toutes les attentions, jamais le corps n’a été autant célébré que comme «le plus bel objet de consommation» passant de la négation au culte: «Pendant des siècles, on s'est acharné à convaincre les gens qu'ils n'en avaient pas... on s'obstine aujourd'hui systématiquement à les convaincre de leur corps " (Baudrillard 1970: 200). Paraître jeune et en bonne santé est devenu prioritaire, demandant des transformations physiques de plus en plus nombreuses afin de refléter une image idéale. L'apparence corporelle est sacralisée, se soumettant aux techniques du sport et de la chirurgie; la maitrise du corps modelé et toujours à parfaire, s'approchant de ce à quoi il voudrait ressembler, donnerait un sens à l'être qui tente ainsi de retarder la mort (Queval 2008: 25). Si l'on peut s'interroger sur une telle revalorisation (Guyot-Roussel 2005), il n'en demeure pas moins que le corps se trouve à l'articulation de l'individu et du groupe, de la nature et de la culture, de la contrainte et de la liberté, du déni et de la reconnaissance. Loin d'être soumise à la sacralisation, la corporéité dans Tejas Verdes. Diario de un campo de concentración chileno de l'écrivain Hernán Valdés (Valdés 1996),

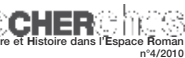


est placée au centre d'un enjeu politique essentiel opposant domination et résistance, oubli et mémoire.

Né en 1934, Hernán Valdés, se fait remarquer et connaître par ses recueils de poèmes puis par ses romans, Cuerpo creciente (Valdés 1966), Zoom (Valdés 1971), qui privilégient des personnages pris entre leur soif d'idéal et un monde marqué par l'absurde. Hernán Valdés fut contraint de s'exiler après le coup d'État. Car, en mettant violemment un terme, le 11 septembre 1973, aux trois années de gouvernement dirigé par le président Salvador Allende, la junte militaire qui prit alors le pouvoir, entreprit une sanglante "croisade» contre l'Unité Populaire (Moulian 1997: 175) afin d'en effacer toutes les traces, et reconvertir le pays à l'ancien ordre moral et économique. Inquisitoriale, fanatique et totalitaire à la fois, elle isola et contrôla les individus en ayant sur eux un droit de vie et de mort. Elle alla jusqu'à les engloutir en les faisant disparaître doublement: elle les effaça temporairement du monde en les séquestrant, ou bien les annula, anéantissant même les corps morts. Un dispositif méthodique mêlant terreur et élimination assura efficacement la longévité d'une tyrannie qui marqua de son sceau l'identité de la nation entière, les principaux responsables continuant à bénéficier d'une totale impunité bien après la fin de ce régime.

Mettant à nu les aspects les plus cruels de la dictature, Hernán Valdés choisit de montrer ce qu'il observa de près durant sa séquestration en publiant Tejas Verdes. Diario de un campo de concentración chileno, durant l'année même où les faits décrits se produisirent, à Barcelone où il avait trouvé refuge avant de s'installer définitivement en Allemagne. Hernán Valdés y fait le récit de ce qu'il endura à «Tejas Verdes» lors de sa détention, durant un mois au début de l'année 1974. Cet ouvrage ne paraîtra qu'en 1996 au Chili, plus de vingt années après la première édition espagnole. Tout en se situant dans la continuité des différentes productions d'Hernán Valdés, Tejas Verdes. Diario de un campo de concentración chileno décrit une lente dégradation, d'autant plus violente qu'elle fut imposée et vécue dans la propre chair de l'auteur. Cherchant à émouvoir comme l'énonce le pacte d'écriture et de lecture rappelé dans le «péritexte» (Genette 1987: 10), ce témoignage introspectif restitue le déroulement et les conditions extrêmes de son enfermement, depuis l'arrestation dans l'appartement de Santiago jusqu'à la libération soudaine dans une rue de la capitale. Grâce à des stratégies d'écriture privilégiant la prise de conscience du récepteur, ce récitlimite à bien des égards est rythmé par la narration quotidienne qui rapporte 
les différentes étapes du parcours d'Hernán Valdés. Le journal restitue les mauvais traitements infligés à son corps, reflétant les tourments subis par la nation entière que le coup d'État déposséda brutalement de son passé. Le corps brutalisé devient un texte-preuve des souffrances du pays, de tous les sacrifiés. Si la traduction fidèle des maux en mots demeure pourtant impossible selon Hernán Valdés, ce dernier s'engage contre la mutilation de la mémoire durant la dictature, puis contre le besoin d'oubli d'une démocratie préoccupée avant tout de cohésion nationale et de croissance économique. Son écriture devient ainsi le «lieu de mémoire» (Provost 2001: 37-38) des êtres humiliés, détruits, disparus, qui retrouvent la dignité et l'humanité qui leur furent niées, qui reprennent corps grâce aux signes.

Parmi les nombreux récits autobiographiques de victimes de la répression, Tejas Verdes. Diario de un campo de concentración chileno a une double particularité: d'une part, il constitue le premier texte qui transcrit une expérience concentrationnaire chilienne (Díaz Cid 2007), révélant l'existence et le rôle du centre de torture "Tejas Verdes" situé à 200 kilomètres de la capitale, qui fonctionna dès la prise du pouvoir des militaires. D'autre part, son auteur, un intellectuel soutenant l'Unité Populaire et travaillant au «Centro de Estudios de la Realidad Nacional» créé sous le gouvernement de Salvador Allende, n'est pas membre d'un parti politique. Loin d'utiliser un langage militant, il décrit les faits et ses réflexions de façon méthodique, presque documentaire. Comme Primo Levi qui publia dès 1947 Si c'est un homme (Levi 2002), Hernán Valdés réagit en écrivain dès sa remise en liberté en faisant sienne la phrase du journal de Kafka «Moi, j'écrirai en dépit de tout, à tout prix» : il obéit au besoin impérieux de communiquer ce qu'il vécut, et de diffuser son témoignage en le faisant publier.

Comme l'indique son titre explicite, Tejas Verdes. Diario de un campo de concentración chileno utilise la structure du journal intime, "diario", s'appropriant un genre qui permet au sujet de se confier: il rapporte, jour après jour, du mardi 12 février au vendredi 15 mars 1974, l'enfermement vécu par l'auteur. Les phrases initiales de la «Nota preliminar» que Hernán Valdés rédigea en 1996 à l'occasion de la première édition chilienne de son livre, rappellent le contexte précis de son élaboration: «Este libro fue escrito hace 22 años, en Barcelona, donde aterricé ... tras salir yo del campo de concentración de Tejas Verdes» (Valdés 1996: 3). Ainsi la «Nota preliminar» superpose quatre temporalités: celle de l'expérience concentrationnaire passée, celle de sa rédaction dès l'éloignement de la patrie, celle de la parution initiale en Espagne la même année, et enfin 
celle de la publication tardive au Chili après vingt-deux ans d'attente. Un tel décalage entre le temps de l'écriture et celui de la lecture confère une permanence et une actualité renouvelée à la dénonciation d'Hernán Valdés, document renvoyant à l'ancien régime militaire. En effet, la démocratisation chilienne se tourna, après la longue dictature, vers l'apaisement politique de la nation, vers la modernité économique, tardant à s'intéresser à "un passéqui ne passe pas» (Conan 1994): «La sociedad chilena está bastante ocupada con su presente y su futuro, con sus alianzas tácticas o estratégicas, con sus negocios, con su reconquistada 'normalidad'» (Valdés 1996: 4).

Insistant sur l'aspect référentiel de son ouvrage, Hernán Valdés reprend, dans son introduction péritextuelle, les termes mêmes du premier prologue de la publication originale espagnole pour justifier le choix délibéré du journal; selon ses déclarations, il rédigea son témoignage à chaud, presque immédiatement après avoir dû quitter le Chili: «...fue escrito al «calor de la memoria», sin mayor elaboración literaria, y sin otra pretensión que la de conmover la opinión pública» (Valdés 1996:3). Ainsi, le journal intime n’en est pas un véritable puisqu'il n'a pu être tenu d'une geôle à l'autre, durant l'emprisonnement dans le camp. Néanmoins, Hernán Valdés le revendique ouvertement comme stratégie d'écriture pour donner plus d'authenticité et de sincérité à sa narration : il apparaît être alors à la fois la production la plus utile, la plus rapide et la plus vraie pour restituer, dans l'urgence, son parcours à l'intérieur même du système répressif. Rendant plus véridiques encore les faits vécus, cette élaboration postérieure a pour rôle essentiel de sensibiliser le lecteur grâce à l'immédiateté qu'elle implique paradoxalement, grâce à la première personne du singulier et à l'épanchement qu'elle suppose.

Tirant toute sa force du croisement et de l'imbrication de deux modalités méprisées car non littéraires, le témoignage et le journal intime, le récitlimite de Hernán Valdés allie simulacre et vérité de l'expérience individuelle. Grâce à cette hybridité, il tente de se donner une forme autre, vraisemblable, documentaire, explicative et presque pédagogique pour mieux rendre compte d'une situation extrême: il dirige les informations directement au lecteur pour mieux provoquer son indignation. Aussi le journal de vie du prisonnier rédigé au présent, linéaire, insiste-t-il sur le contexte historique et politique en renvoyant au passé, à l'Unité Populaire: «Pues el poeta P. quizá para vengarse de no haber recibido los honores que esperaba durante el gobierno de Allende, ... ahora ha asumido la sucia responsabilidad de dirigir un departamento en la Universidad de Chile...» (Valdés 1996: 87). 
Cette introspection souligne le lent et minutieux ordre chronologique pour refléter l'enfermement du corps; il s'efforce également de conduire le récepteur vers la prise de conscience de l'étirement du temps, de la durée insupportable de la séquestration et de la constance de son horreur. La contrainte de la succession des annotations journalières, depuis la date de l'arrestation à l'ultime, celle de la libération, qui encadrent le discours, permet aussi de plonger dans les pensées, les doutes, les peurs de la voix narrative, voix d'une conscience dont l'indépendance, la subjectivité sont affirmées dès le péritexte: «El autor no pertenece a ningún partido, no es miembro de ninguna institución; por lo tanto no "representa» una experiencia política corporativa o colectiva. Su experiencia es individual... A lo que hay que agregar que su visión del proceso chileno es crítica y su conducta antiheroica. Y lo que es peor: crítica fundada en su pura subjetividad» (Valdés 1996: 3-4)

La série de négations et le fait de parler de soi comme d'un autre, comme d'un personnage, par l'emploi de la troisième personne du singulier, s'efforcent de mettre en évidence la liberté, la sincérité et la singularité de sa dénonciation qui, en étant étrangère à toute récupération, ne peut être mise en doute. Le pacte d'écriture et de lecture s'établit ainsi sur l'exemplarité de la reconstruction qui, en s'éloignant de toute position partisane, projette le lecteur dans le présent de l'auteur-narrateur, tous deux suivant simultanément l'enchaînement inéluctable des événements dans leur déroulement, jusqu'au double aboutissement de l'ouvrage. En effet, la dernière journée transcrite est celle de la brusque remise en liberté, tout aussi arbitraire que la détention, qui correspond au terme de la lecture et à l'achèvement même du livre. L'«expulsion» du camp implique une circularité en renvoyant à la «Nota preliminar", à l'exil qui en est la suite logique et qui permet à la fois la survie, la reconstitution du vécu par l'écriture et l'indignation espérée du récepteur.

Le témoignage du narrateur se structure également sur un besoin constant d'évaluer ce qu'il expérimente, pour en proposer une vision personnelle dès les premiers paragraphes: «El golpe ha deshecho toda clase de relaciones, y los residuos flotantes de esta catástrofe nos hemos encontrado para constituir otras, insólitas, precarias» (Valdés 1996: 9). Commentaires, analyses et autocritiques reflètent la clairvoyance de l'auteur-narrateur tout en appuyant l'«effet de réalité» recherché pour mieux convaincre. La préoccupation de l'efficacité de la communication des faits et de sa recevabilité rappelle celle de Jorge Semprún s'interrogeant, ainsi que ses compagnons survivants, sur 
la manière de traduire l'expérience concentrationnaire, de décrire le camp de concentration dans l'espace textuel: "Comment raconter une vérité peu crédible, comment susciter l'imagination de l'inimaginable, si ce n'est en élaborant, en travaillant la réalité, en la mettant en perspective? Avec un peu d'artifice, donc!» (Semprún 1994: 166).

Car il s'agit bien pour $\mathrm{H}$. Valdés de toucher le lecteur en l'approchant au plus près de ce qui demeure incompréhensible. Le pacte de vérité engage le témoin à tout exposer. Aussi, dès la phrase initiale, le narrateur "autodiégétique» (Genette 1972: 253) se divise-t-il en «je narrant», observateur, et en "je narré», observé, révisant sans cesse ses propres réactions et pensées, dès les instants antérieurs à l'arrestation imminente: "¿Qué hago exactamente aquí en casa, a las 6.30 de la tarde? De un modo coherente no podría explicárselo a nadie. Espero que pase el tiempo, que mueran las horas» (Valdés 1996: 9). Par ce dédoublement, il est l'objet même de son regard critique, du questionnement qui ouvre le journal annonçant ses nombreuses interrogations et remises en cause au sein du récit: "Mi conducta durante el allanamiento me parece de pronto ridícula» (Valdés 1996: 30). La force de sa dénonciation et de ses révélations repose sur la lucidité qu'il tourne également vers lui-même malgré son statut de victime. Ainsi le pacte d'écriture et de lecture implique de ne rien cacher, de fouiller l'intime, de décrire en langage cru les mauvais traitements endurés durant la détention, et les traces laissées sur une corporéité qui affiche les preuves de la répression.

Le journal rapporte, avec une clairvoyance aiguë, les différentes étapes du martyre d'H. Valdésà partir de son arrestation, le cours de sa vie étant suspendu durant un mois. Cette expérience le fait passer de la surprise initiale à la connaissance de l'aliénation physique. La détention, de la geôle clandestine au camp de concentration implique une progressive dégradation physique. Au cours de l'enfermement, le corps est agressé de façon programmée, les tortures et leurs conséquences étant détaillées, mettant en évidence le dédoublement de la voix de la narration: le je narrant scrute les réactions et les douleurs du je narré, laissant une conscience affleurer: «Escucho mi propia voz con extrañamiento y vergüenza ... Y luego el tono quejumbroso, casi implorante, que he dado a la frase» (Valdés 1996: 29); «Mi voz debe sonar patética» (Valdés 1996: 41). Cette division dans l'autoreprésentation enlève tout dramatisme à la restitution des souffrances endurées en provoquant une distanciation. 
Dès l'arrestation dans l'appartement où vit l'auteur-narrateur, la logique des interrogatoireslui échappe, violence et absurde étant de mise: «...el cañón de una metralleta se ha incrustado en mis costillas... La inutilidad de las explicaciones que les doy me desalienta, comienzo a sentirme insensatamente atrapado» (Valdés 1996: 23). À partir du trajet vers la première prison, entrant dans un monde inconnu, le corps est dépersonnalisé; aveuglé, attaché, il est laissé aux sens de l'ouïe et de l'odoratqui ne lui fournissent que des indications approximatives du lieu où il se trouve et de ce qui l'entoure: «El ruido anuncia una puerta de fierro con cerrojos... Olor a fuertes orines...» (Valdés 1996: 25). Privé de tout repère précis, assailli de multiples questions laissées sans réponse et de conjectures de toutes sortes, l'auteur-narrateur insiste sur son isolement et sur la situation d'infériorité qui le rend vulnérable face à ses bourreaux: «De modo que estaba bien condicionado, emocionalmente, para someterme a la agresión, al rol de víctima» (Valdés 1996: 31).

Cette solitude est d'autant plus évidente et désespérante face au pouvoir illimité des divers groupes des agresseurs auxquels il est livré dans la geôle clandestine puis dans le camp de concentration. Ces espaces fermés constituent des lieux d'exaspération de l'attente qui se prolonge et dans laquelle il est plongé indéfiniment, le fragilisant davantage en limitant ses mouvements: "El frío ha comenzado a producirme una sensación de enfermedad, de fiebre, de desamparo físico. El culo me duele atrozmente. No hay una sola posición ... que no haya ensayado" (Valdés 1996: 32). Unie à l'enfermement, aux cellules closes ou souterraines, à l'inactivité insupportable, cette mise à disposition totale dans un temps existentiel intensifié, qui semble stagner, s'ajoute au manque de sens de la détention elle-même prise entre routine et terreur. La modification du corps qui accumule crasse et douleur, souligne sa dégradation progressive reflétant la perte de l'individualisation au fil des jours: «El aspecto de ellos es lamentable y el mío debe ser idéntico: demacrados, barbudos, camisas desencajadas, ropas sucias y arrugadas» (Valdés 1996: 49) ; "Me silban los oídos, mi piel empieza a desaparecer bajo la barba. No doy conmigo, no sé qué soy exactamente después de todo lo que ha sucedido" (Valdés 1996 : 72).

La culmination angoissante de l'interrogatoire redouté et espéré à la fois dans cette attente interminable rend acceptable l'inacceptable. La séance de torture devient inéluctable; il est impossible d'y échapper. A l'absurde et à l'horreur des abus inexorables dont sont capables les hommes, s'ajoute l'inutilité de toute révolte et de toute préparation, car ils dépassent tout ce 
qui est pensable: «Siento pena de mi cuerpo. Este cuerpo va a ser torturado, es idiota. Y sin embargo es así, no existe ningún recurso racional para evitarlo...» (Valdés 1996: 115). La victime ne peut s'y soustraire ni ne peut fuir; elle doit s'y soumettre afin d'avoir une possibilité d'y survivre, paradoxalement: «... sólo aceptando nuestra culpabilidad tenemos la esperanza de salir con vida» (Valdés 1996: 144). De la prison clandestine au camp, les militaires utilisent les mêmes techniques qui gagnent en intensité dans «Tejas Verdes »; ils forment des tribunaux qui interrogent et répondent à la fois pour mieux utiliser, non pas la loi qu'ils ne respectent pas, mais l'arbitraire. L'échange instauré entre tortionnaires et torturé est un dialogue altéré, aliéné; il prétexte les coups portés au corps: «Niego violentamente y como respuesta me llega un golpe en los riñones, que no siento como dolor sino como una especie de chispazo azul en esa zona» (Valdés 1996: 41). Les questions même des interrogatoires brutaux semblent être sans fondement, leur logique et leur cohérence étant incertaines au-delà de la déstabilisation et de la terreur ainsi provoquées: «Parece que el sistema de los torturadores para obtener informaciones se basa un tanto en el cálculo de probabilidades de una lotería» (Valdés 1996: 144).

La voix du récit se décrit comme un naïf, un Candide précipité dans la tourmente, dérouté par des situations incompréhensibles qui le dépassent: "Quedo definitivamente con una fama de tonto del regimiento.» (Valdés 1996 : 109). En effet, il en partage l'étonnement, l'ahurissement, l'inquiétude, l'effroi face aux épreuves qu'il traverse, et face au fonctionnement même des centres de détention. Dans cette descente aux enfers, il expérimente, comme lui, le «mal physique», selon le terme de Voltaire: le froid, la faim, la douleur physique le frappent constamment, revenant de manière obsessive dans le texte: «...el frío se expresa como dolor, como dolor óseo, muy interior» (Valdés 1996: 51). Il est également confronté au «mal moral» qui y tient une place prépondérante à travers l'arbitraire, la stupidité et la férocité fratricide des militaires; ces derniers n'hésitent pas à dénigrer, à manipuler, à torturer, à tuer ceux qu'ils soupçonnent et traquent. Les mauvais traitements sont des actes de guerre, de combat qui mettent en déroute ceux qu'ils considèrent comme leurs ennemis: "Ustedes son prisioneros de guerra. Al menor intento de fuga, disparamos al cuerpo» (Valdés 1996: 49).

L'arrivée à «Tejas Verdes» montre le choc du premier contact concentrationnaire que souligne l'aspect étrange, indéchiffrable d'un lieu séparé et invisible de l'extérieur, une géographie parallèle au monde «normal» qui continue d'exister de façon insolente: «Veo algunos vehículos cruzando 
el puente, las luces de las casas que bordean el río. Existe, evidentemente, una vida cotidiana a pocos metros de aquí y, más que eso, una vida festiva de quienes pasan sus vacaciones.» (Valdés 1996: 72). Comme tous les camps de concentration, "Tejas Verdes» est doté d'un ordre négatif détruisant la vie au lieu de la préserver; ses règles menent à la torture, à la disparition, à la mort, ce qui fonde son illisibilité même: "Algo que nos subleva a todos es la irracionalidad de nuestro encierro... que nos tengan echados aquí como perros sarnosos... cualquier condena de prisión sería mil veces más soportable que este encierro extrarreal...» (Valdés 1996 : 106).

Le narrateur prend également une dimension christique, victime innocente passant par les stations d'un véritable chemin de croix. Il est ancré dans l'instant, ne pouvant se projeter dans le futur qui est trop angoissant car prometteur de brimades, de menaces. Par ailleurs, il est littéralement impensable: "No puedo representarme sino este ahora, este estar-aquí, maniatado, ciego, impregnándome del avasallador olor a orines » (Valdés 1996: 26). Ses fonctions vitales sont altérées dans le quotidien de l'emprisonnement: "Me hallo en un estado onírico, viciado, no puedo concentrarme en nada. Seis días sin cagar y seis noches sin dormir. Y atormentado de frío" (Valdés 1996: 85). Un tel espace prive le séquestré de toute humanité, de toute intimitéavec, en particulier, l'humiliation des tinettes publiques permises à heures fixes: «Nos bajamos los pantalones con prisa, tratando de equilibrarnos sobre los dos troncos también chorreados de mierda. Quedamos culo contra culo ...La mierda de Rubén sale ante mis propios ojos...» (Valdés 1996: 79). Tout est fait pour que règnent abjection et répugnance viscérale imposées par un autoritarisme qui limite les nécessaires mécanismes corporels.

Les interrogatoires accumulent injures et tourments cruels pour soumettre le corps et lui faire perdre ses caractéristiques individuelles: «Así que vos sois maricón... Otra descarga de corriente. Vuelvo a caer y vuelven a levantarme a patadas... Soy una pura masa que tiembla y que trata todavía de tragar aire» (Valdés 1996: 118). Si les tortionnaires s'attaquent à la corporéité, c'est pour mieux affirmer leur pouvoir absolu en niant la dignité de l'être. Le corps encagé et battu est décrit dans sa matérialité de façon presque clinique, privé de toute défense; la souffrance se propage à l'assemblage d'os, de chair, d'organes, le narrateur utilisant des comparaisons en s'efforçant de traduire les effets vifs, tranchants des tortures: "Alguien me da, con toda la fuerza de un brazo, un puñete en la boca del estómago. Es como si me cortaran en dos» (Valdés 1996: 117); «Es como si me arrancaran el sexo de raíces, como 
una dentellada que me deja abierto y, arriba, en la boca, como una explosión que volara toda la carne, que dejara los huesos de la cara y del cuello al desnudo, los nervios petrificados, en el vacío.» (Valdés 1996: 127).

Le corps malmené apparaît tordu de douleur, crucifié sous les supplices subis dont il garde longtemps les marques, les stigmates: "Mis heridas ya están secas y los hematomas pasan del negro al lila» (Valdés 1996: 141). L'auteur-narrateur le décrit en proie à des réactions jamais éprouvées aussi intensément, dont la force le surprend et le dépasse, peinant à en refléter la substance, la densité: "No sé cómo decir que estoy temblando sin que esto parezca una figura retórica. Las rodillas, los hombros, el pecho, los músculos del cuello y la nuca se estremecen cada cual independiente, con contracciones distintas» (Valdés 1996: 114). Il échappe à son contrôle car les mauvais traitements s'appliquent à dissocier méthodiquement la dualité traditionnelle formant l'être: en dominant l'espace corporel par la terreur, les tortionnaires cherchent à s'emparer de la volonté de la victime et à l'en déposséder: "- ${ }_{i} Y$ dijo que estaba colaborando en la campaña internacional del marxismo contra Chile? Por supuesto que sí, todo lo que quieran.» (Valdés 1996: 128). Le corps meurtri du supplicié ne répond plus à sa raison et suit celle des bourreaux: «... no seré una persona, no tendré expresiones. Seré sólo un cuerpo, un bulto, se entenderán sólo con él» (Valdés 1996: 115); "No puedo soportarlo más... La corriente me muerde los huesos, me triza las rodillas. Quisiera poder decir cualquier cosa que pusiera fin a las descargas...» (Valdés 1996 : 124). Sa conscience quitte le corps incontrôlable dominé par l'horreur.

La torture détruit toute résistance de ce corps-pensant qui est amené au bord du gouffre, du néant ; il est anéanti et vidé pour être rempli d'une mémoire, d'une histoire qui lui sont imposées pour mieux le condamner: «Mi cerebro está en blanco. Trato de buscar cuándo fue junio, dónde fue junio, dónde está junio. Nada» (Valdés 1996: 123); «No encuentro nada. No tengo memoria. No logro recordar en qué mes estamos, para entonces calcular cuándo fue enero" (Valdés 1996: 125); "Me dispongo otra vez a morir... Vacío, en blanco...» (Valdés 1996: 127). Ainsi, le journal retrace une initiation inversée, funeste, la victime passant de l'ignorance à la connaissance du mal absolu qui punit, qui broie chair et âme, qui la culpabilise, l'amène à contribuer à son tour à la répression par de fausses déclarations dictées, devenant un complice obligé de ses propres bourreaux pour ne plus être torturé: «Es una declaración. Están mis datos personales... Están los nombres de quienes estuvieron de acuerdo... Tomo el lápiz que 
hay sobre la mesa y firmo con una repugnancia ostensible... El temor de que me van a usar ha sido confirmado » (Valdés 1996: 150-151). La lâcheté retranscrite avec froideur ne fait que souligner l'aspect redoutable, radical de la violence des supplices qui soumet et annihile le corps, atteignant ainsi l'esprit: «Porque lo que yo sabía de la maldad eran puras caricaturas, pura literatura» (Valdés 1996 : 49). En ne dissimulant rien de sa chute et du savoir qu'il acquiert ainsi, Hernán Valdés affronte la vérité du corps-preuve nié dans son humanité et dans sa définition même; dépassant le drame personnel, sa propre remise en cause permet de questionner la société entière qui, comme lui, ne prêta pas attention aux menaces.

La voix du récit observe et analyse avec précision, et sans concession avec elle-même, les mécanismes de la terreur, l'horreur de la division de son corps: "Así, entonces, en la misma medida en que estos momentos de esfuerzo reflexivo nos restituyen nuestra humanidad, así también nos someten a la angustia de esa condición, a una penosa lucidez que nos da escalofríos" (Valdés 1996: 148). En décrivant la régression des prisonniers affamés et confrontés sans cesse à l'arbitraire concentrationnaire, il s'identifie au groupe en utilisant la première personne du pluriel: "Sin darnos cuenta vamos adoptando un comportamiento infantil... nuestra inteligencia empieza a aceptar esta irracionalidad» (Valdés 1996: 60). Le camp de concentration apparaît en quelque sorte comme un condensé du territoire national par la variété de ceux qui y sont internés: «De modo que somos una especie de mosaico informe de la sociedad chilena» (Valdés 1996: 102). Le narrateur fait donc corps avec une patrie ingénue qui ignore qu'elle enfante des démons. Sa corporéité martyrisée reflète le corps-nation soumis aux tourments, le citoyen se métamorphosant en un prisonnier qu'aucune loi ne protège et contre lequel s'exerce un pouvoir absolu.

La lucidité revendiquée l'amène à distinguer clairement les suppliciés des bourreaux; aussi tente-t-il d'être clairvoyant envers les processus en cours à l'intérieur de la nation qui amenèrent à cette division. Hernán Valdés en livre une interprétation en 1974, coïncidant avec ce que Carlos Cerda définit plus tard, en 1996, comme "nuestra barbarie», dans son roman Una casa vacía (Cerda 1996: 224). En effet, le régime militaire est une version chilienne du "fascisme", utilisant la torture pour terroriser la population et affirmer ainsi son autorité. Cela le conduit à questionner la démocratie elle-même qui n'a pas été capable de le voir naître, a refusé son évidence et ne l'a pas l'empêché: «¿Cómo no haber comprendido que todos esos que nos parecían enemigos inofensivos... formaban un frente de clase único con la ultraderecha y tenían 
un plan de guerra y de exterminio?» (Valdés 1996: 147). Elle n'a pas vu les dangers venant de son sein même, et elle a produit des monstres, des barbares prêts à tout pour éliminer un gouvernement honni, suivant un programme élaboré de longue date: «¿Dónde estaban estos miles y miles de hombres que a través del país son nuestros asesinos?» (Valdés 1996: 147). En dénonçant cet aveuglement antérieur sur la véritable nature des événements qui annonçaient le coup d'État et la dictature, la question de la présence du mal radical est au cœur de son témoignage. Il cherche le moyen de comprendre ce qui reste incompréhensible, de percer le mystère de la transformation des hommes en forces maléfiques qui représentent un péril constant.

De fait, ses productions postérieures à l'expérience concentrationnaire, A partir del fin (Valdés 1984), La historia subyacente (Valdés 1984), interrogent, à travers le même personnage, Hache, l'évolution brutale de l'histoire chilienne. En s'efforçant de dénouer les causes économiques et politiques du putsch et d'en révéler tous les aspects à la lumière de la violence qu'il engendra, il en propose, dans ces deux ouvrages, une lecture qui a été fort critiquée puisqu'il n'hésite pas à y souligner, avec virulence, les responsabilités qu'auraient eues, à son avis, les dirigeants de l'Unité Populaire dans leur propre défaite: leur naïveté face à la peur, à l'hostilité et à la haine des secteurs opposés aux changements mena à une catastrophe inévitable. Selon Hernán Valdés, la légitimité et la légalité sur lesquelles s'appuya le gouvernement de l'Unité Populaire se seraient retournées contre lui-même avec une force effroyable, laissant place à la vengeance d'une bourgeoisie disposée à une confrontation fratricide, à toutes les atrocités pour reprendre le pouvoir perdu.

Le corps meurtri d'Hernán Valdés est exposé dans Tejas Verdes. Diario de un campo de concentración pour témoigner de l'entreprise destructrice de la dictature qui effaça, par la terreur, les traces des suppliciés en leur imposant silence, en les éliminant. Les descriptions anatomiques insistent sur les marques des blessures comme autant de preuves des méthodes utilisées durant le régime militaire pour détruire l'humanité des victimes. À travers son corps désarticulé, Hernán Valdés restitue la dignité perdue de tous ceux qui furent martyrisés comme lui; transformé en revenant dans tous les sens du terme - il revient du camp, et il est habité par les fantômes de ceux qui y restèrent -, il parle par délégation, selon l'expression de Primo Levi, pour ceux qui n'ont pu laisser de trace de leurs souffrances. Le témoignage acquiert ainsi toute sa valeur. Son destin individuel reflète celui d'une nation malmenée, plongée dans l'horreur et la violence de l'arbitraire, engendrant sans le savoir les monstres qui la déchirèrent. Se tournant vers le lecteur et 
tentant de comprendre, l'écriture engagée de Hernán Valdés questionne l'histoire, et révèle, dès 1974, la véritable nature du régime autoritaire chilien, une forme du «fascisme» prétendant s'approprier des êtres en les démembrant, en les déshumanisant. Reconstitué dans l'espace des signes, le corps torturé du survivant se dresse en mémoire de la barbarie. Écrire le corps est la condition de la liberté: il devient donc un acte politique pour échapper à un anéantissement programmé, pour lutter contre la tentation de l'oubli, pour résister à l'ignorance et à l'indifférence.

\section{Bibliographie}

Baudrillard, Jacques, 1970, La société de consommation, Paris, Gallimard.

Cerda, Carlos, 1996, Una casa vacía, Santiago, Alfaguara.

Conan, Eric, et Rousso, Henry, 1994, Vichy, un passé qui ne passe pas, Paris, Fayard. Díaz Cid, César, 2007, «El discurso testimonial y su análisis literario en Chile», in

Documentos lingüísticos y literarios, Santiago, $\mathrm{n}{ }^{\circ} 30,2007$, www.humanidades.uach.cl/documentos_linguisticos/document.php?id=1354.

Genette, Gérard, 1972, Figures III, Paris, Éditions du Seuil, p. 253.

Genette, Gérard, 1987, Seuils, Paris, Éditions du Seuil.

Guyot-Roussel, Marine, 2005, «Le corps retrouvé», in Mag philo, Automne 2005, www.cndp.fr/magphilo/philo14/corpsretrouve.htm.

Queval, Isabelle, 2008, Le corps aujourd'hui, Paris, Gallimard.

Levi, Primo, 2002, Si c'est un homme, Paris, Julliard (rééd.; traduction de Martine Schruoffeneger).

Moulian, Tomás, 1997, Chile actual. Anatomía de un mito, Santiago, LOM Ed.

Provost, Alain, 2001, «Les lieux de mémoires », in Cahiers Français, La Documentation française, Paris, $n^{\circ} 303$, juillet-août 2001, p. 37-38.

Semprun, Jorge, 1997, L'écriture ou la vie, Paris, Gallimard, p. 166.

Valdés, Hernán, 1966, Cuerpo creciente, Santiago, Zig Zag.

Valdés, Hernán, 1971, Zoom, México, Siglo XXI.

Valdés, Hernán, 1984, A partir del fin, México, Era.

Valdés, Hernán, 1984, La Historia subyaciente, Berlin, Rotbuch Verlag.

Valdés, Hernán, 1996, Tejas Verdes Diario de un campo de concentración chileno, Santiago, Ed. LOM-CESOC, Col. Septiembre. 